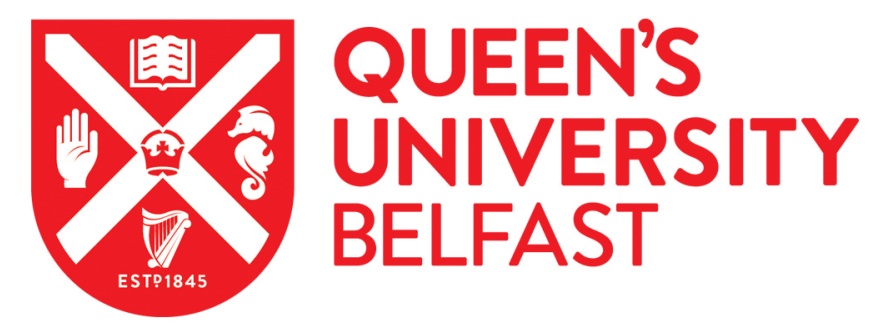

\title{
Relationships between alcoholic beverages and cardiovascular risk factor levels in middle-aged men the PRIME study
}

Marques-Vidal, P., Montaye, M., Haas, B., Bingham, A., Evans, A., Juhan-Vague, I., Ferrieres, J., Luc, G., Amouyel, P., Arveiler, D., Yarnell, J., Ruidavets, J. B., Scarabin, P. Y., \& Ducimetiere, P. (2001). Relationships between alcoholic beverages and cardiovascular risk factor levels in middle-aged men the PRIME study. Atherosclerosis, 157(2), 431-440.

Published in:

Atherosclerosis

Queen's University Belfast - Research Portal:

Link to publication record in Queen's University Belfast Research Portal

\section{General rights}

Copyright for the publications made accessible via the Queen's University Belfast Research Portal is retained by the author(s) and / or other copyright owners and it is a condition of accessing these publications that users recognise and abide by the legal requirements associated with these rights.

Take down policy

The Research Portal is Queen's institutional repository that provides access to Queen's research output. Every effort has been made to ensure that content in the Research Portal does not infringe any person's rights, or applicable UK laws. If you discover content in the Research Portal that you believe breaches copyright or violates any law, please contact openaccess@qub.ac.uk. 


\title{
Relationships between alcoholic beverages and cardiovascular risk factor levels in middle-aged men, the PRIME study
}

\author{
Pedro Marques-Vidal a , Michèle Montaye ${ }^{\mathrm{b}}$, Bernadette Haas ${ }^{\mathrm{c}}$, Annie Bingham ${ }^{\mathrm{d}}$, \\ Alun Evans ${ }^{\mathrm{e}}$, Irène Juhan-Vague ${ }^{\mathrm{f}}$, Jean Ferrières ${ }^{\mathrm{a}, *}$, Gérald Luc ${ }^{\mathrm{b}}$, \\ Philippe Amouyel b, Dominique Arveiler ${ }^{\mathrm{c}}$, John Yarnell e, Jean Bernard Ruidavets a, \\ Pierre-Yves Scarabin ${ }^{\mathrm{d}}$, Pierre Ducimetière ${ }^{\mathrm{d}}$ \\ a INSERM U518, Faculté de Médecine Purpan, Département d'Epidémiologie, ler ét., 37, Allées Jules Guesde, 31073 Toulouse Cedex, France \\ ${ }^{\mathrm{b}}$ INSERM U508, Institut Pasteur de Lille, Lille, France \\ ${ }^{\mathrm{c}}$ MONICA-Strasbourg, Laboratoire d'Epidémiologie et de Santé Publique, Strasbourg, France \\ d INSERM U258, Hôpital Paul Brousse, Villejuif, France \\ e Belfast-MONICA, Department of Epidemiology and Public Health, The Queen's University of Belfast, Belfast, UK \\ ${ }^{\mathrm{f}}$ Laboratory of Haematology, La Timone Hospital, Marseille, France
}

Received 7 August 2000; received in revised form 6 November 2000; accepted 9 November 2000

\begin{abstract}
The relationships between alcoholic beverages and cardiovascular risk factors were assessed in 6730 men living in France or Northern Ireland. In France, all alcoholic beverages were significantly correlated with body mass index (BMI), systolic (SBP) and diastolic blood pressure (DBP), high density lipoprotein (HDL) parameters, PAI-1 and Factor VII, whereas only wine was negatively related with fibrinogen levels. After adjusting for center, age, BMI, educational level, smoking and marital status, wine had a lesser effect on blood pressure, triglyceride, apo B and LpE:B levels than beer. Wine was associated with lower fibrinogen levels and beer with higher PAI-1 activity levels independent of the amount of alcohol consumed. In Northern Ireland, wine was negatively correlated with BMI, triglycerides, LpE:B and fibrinogen, whereas beer was positively correlated with SBP and DBP, triglycerides, HDL, apoprotein A-I and fibrinogen. Multivariate analysis showed wine to be positively associated with HDL parameters, and negatively with fibrinogen levels. Wine was also associated with higher LpA-I levels and lower fibrinogen levels independent of the amount of alcohol consumed. We conclude that alcohol consumption is related to lipid, lipoprotein and haemostatic variables, but the magnitude of the relationships depends on the type of alcoholic beverage. Also, some effects might be related to non-alcoholic components. (C) 2001 Elsevier Science Ireland Ltd. All rights reserved.
\end{abstract}

Keywords: Alcohol; Apolipoproteins; Blood pressure; Fibrinogen; HDL; Total cholesterol; Triglycerides

\section{Introduction}

Moderate intake of alcohol has been shown to be inversely related to the incidence of coronary artery disease [1-10]. Although some authors have shown that the protective effect of wine is superior to that of other alcoholic beverages [11-14], these results have not been confirmed in other studies [7,15-17].

The mechanisms by which moderate alcohol con-

\footnotetext{
* Corresponding author. Tel.: + 33-561-521870; fax: + 33-562264240.

E-mail address: ferriere@cict.fr (J. Ferrières).
}

sumption decreases coronary artery disease are complex and multiple. Alcohol intake has been shown to increase high density lipoprotein (HDL) and apolipoprotein A-I (apo A-I) levels [18-26] and to decrease lipoprotein(a) levels [27-29]; moreover, phenolic compounds present in red wine could inhibit lipoprotein oxidation [30-36]. Alcohol consumption has also been shown to influence insulin levels [37] and to affect the activity of proteins involved in the metabolism of HDL [38], although this latter hypothesis remains controversial [39]. Finally, an interaction between alcohol intake and a polymorphism of the cholesteryl ester transfer protein (CETP) gene has been demonstrated [40,41]. 
Thus, although there is definitely a biological effect of alcohol, it is still unclear whether all types of alcoholic beverages exert the same effect on lipid and lipoprotein levels. In a previous report [21], we assessed the relationship between total alcohol consumption and cardiovascular risk factor levels in healthy male subjects living in France and in Northern Ireland. In this study, we use data from the Prospective Epidemiological Study of Myocardial Infarction Study (PRIME), which also involved France and Northern Ireland, to analyze the relationships between different types of alcoholic beverages and the levels of the main cardiovascular risk factors.

\section{Patients and methods}

\subsection{Population sampling}

The PRIME Study was established in 1991 in the populations of the four collaborating centers of Belfast (UK), Lille, Strasbourg and Toulouse (France). The target was to recruit 2500 men, aged 50-59 years, in each center and to follow them for a minimum of 5 years. The sample was recruited to match broadly the social class structure of the background population. The sampling frame was based on industry and various employment groups, and on health screening centers and general practice. Participation was voluntary. Subjects were informed of the aim of the study and those who agreed to take part were given a morning appointment and asked to fast for a period of a minimum of 10 h.

\subsection{Personal and medical history}

Self-administered questionnaires relating to demographic, socioeconomic factors and diet were completed at home by the participants and checked by the interviewer at the clinic. Data were collected on level of education, occupational activity, personal and family history, tobacco and alcohol consumption, drug intake and physical activity.

\subsection{Alcohol consumption}

Alcohol consumption was assessed by a questionnaire where the subject reported his mean consumption (in Units) of wine, beer, cider and spirits for each day of the week. Intake of alcohol (expressed in $\mathrm{ml}$ of pure ethanol/day) was estimated from the average number of $\mathrm{ml}$ of ethanol in a measure of each type of alcoholic beverage; wine, $12 \mathrm{cl}$ serving, 10 or $12 \%$ alcohol $(\mathrm{v} / \mathrm{v})$; beer, $12 \mathrm{cl}$ serving, $5 \%$ alcohol, 25 or $33 \mathrm{cl}$ serving, 6 or $8 \%$ alcohol; cider, $12 \mathrm{cl}$ serving, $5 \%$ alcohol; spirits, 2 or $6 \mathrm{cl}$ serving, 20 or $40 \%$ alcohol.

\subsection{Clinical measurements}

Height and weight were measured by calibrated scales using a standard protocol, and body mass index (BMI) was calculated as weight $/$ height $^{2}\left(\mathrm{~kg} / \mathrm{m}^{2}\right)$. Blood pressure was measured once at the end of the examination after a 5-min rest in the sitting position. Measurements were performed with an automatic device (Spengler SP9), which also recorded heart rate. A standard cuff size was used, but a large cuff was available whenever necessary. At least three measuring devices were available at any time in each center and all three were used equally. In order to avoid systematic differences between centers, the devices were circulated among them. The devices were also recalibrated every 3 months in the co-ordinating center in Paris.

\subsection{Blood sampling and assay procedures}

Subjects were asked to fast for at least $10 \mathrm{~h}$ before blood collection. Venous blood (9 vol.) was collected between 9:00 and 10:00 $\mathrm{h}$ into siliconized vacutainer tubes (Vacutainer, Becton Dickinson) containing 0.11 $\mathrm{M}$ trisodium citrate (1 vol.). Platelet-poor plasma was obtained by centrifugation at $3000 \times g$ and $4^{\circ} \mathrm{C}$ (PAI-1 measurements) or $20^{\circ} \mathrm{C}$ (fibrinogen and Factor VII assay) for $15 \mathrm{~min}$. Aliquots of plasma were immediately transferred into plastic tubes and frozen on-site to $-80^{\circ} \mathrm{C}$. The frozen aliquots were then shipped in batches to the central laboratory in Lille.

Haemostatic variables were measured in the central haemostasis laboratory of La Timone Hospital at Marseille, France. Fibrinogen was measured according to the method of Clauss (Fibriprest automate, Diagnostica Stago). Factor VIIc was assayed in a regular one-stage system using rabbit thromboplastin. Factor VII-deficient substrate plasma was prepared from absorbed bovine plasma and concentrate of human Factors IX, $\mathrm{X}$ and II as described previously [42]. Results were expressed as a percentage of reference plasma. PAI-1 activity was measured by a two-stage amidolytic method using a commercially available kit (Spectrolyse/ pl, Biopool, Umea, Sweden). All the haemostatic tests were performed between January 1991 and 1994. Accuracy and precision of haemostatic assays were assured by a strict internal quality control program. A single batch of normal plasma pool prepared from 50 healthy subjects was used for control purposes. For each assay, 2-4 controls were included in each run of PRIME Study samples. Analysis of internal quality control data showed that laboratory coefficient of variation ranged from 4.3 (fibrinogen) to $9.5 \%$ (PAI-1).

Plasma prepared with EDTA was used for analysis of lipids. Plasma total cholesterol and triglycerides were measured by enzymatic methods using reagents from Boerhinger Mannheim (Mannheim, Germany). The in- 
terassay coefficient of variation for total cholesterol and triglyceride were 2 and $3 \%$, respectively. HDL cholesterol was measured after precipitation of apoprotein B-containing lipoproteins with sodium phosphotungstate-magnesium chloride (Boerhinger Mannheim, Mannheim, Germany). Apoproteins A-I and B were measured by a nephelometric method (Behringwerke, Marburg, Germany). Lipoparticles LpE:B and Lp(a) were assessed using bi-site immunoenzymatic tests. Lipoparticles LpA-I were assessed by electroimmunoassay on ready-to-use plates [43].

\subsection{Statistical analysis}

Statistical analysis was conducted using SAS (SAS Institute, Cary, North Carolina, USA) software. Subjects with a personal history of angina pectoris, myocardial infarction, possible coronary heart disease and treatment for hypertension and/or dyslipidaemia were excluded from the analysis. Univariate analyses were performed using Wilcoxon rank sum test or Spearman correlation. Multiple regression analysis was used to assess the relationships between alcohol intake expressed in $\mathrm{U}$ per day ( $1 \mathrm{U}=15 \mathrm{ml}$ ethanol) and cardiovascular risk factor levels. The effects of the three types of alcoholic beverages (wine, beer and spirits) were analyzed by testing the hypothesis that the corresponding regression coefficients were equal. For multivariate analysis, triglyceride levels were log-transformed. The effect of the type of beverage (independent of its alcohol content) was assessed introducing into the multiple regression a dichotomous variable for each type of beverage, as suggested by [44]. Statistical significance was considered for $P<0.05$.

\section{Results}

\subsection{Population and alcohol consumption}

Of the initial 10595 subjects, 593 were excluded because of a history of angina pectoris, myocardial infarction or possible coronary heart disease, and 1825 because of medical treatment for hypertension or hypercholesterolaemia. Of the 8177 remaining subjects (5926 for France and 2251 for Northern Ireland), 6730 reported consuming alcohol at least once per week (5363 in France and 1367 in Northern Ireland). Their clinical characteristics are summarized in Table 1. French drinkers were significantly older, had a higher BMI, had reached higher education more frequently, smoked less and were more frequently married than Northern Irish drinkers. Alcohol consumption (expressed in $\mathrm{ml}$ of total alcohol per week) was slightly higher in Northern Ireland than in France $(325 \pm 333$ vs. $318 \pm 249 \mathrm{ml}$ of ethanol per week, Kruskall and
Wallis test $P<0.01$ ). When the total alcohol consumption was separated into wine, beer and spirits, wine was most consumed in France, whereas beer and spirits were most consumed in Northern Ireland (Table 1).

\subsection{Univariate correlations between the amount of alcohol consumed and cardiovascular risk factors}

In France, total alcohol consumption was significantly and positively correlated with BMI, blood pressure, lipid and lipoprotein levels, and negatively correlated with $\mathrm{Lp}$ (a) and fibrinogen (Table 2). Conversely, no correlation was found between total alcohol consumption and LpE:B. Similar patterns were found when total alcohol consumption was split into wine, beer and spirits, except that the correlations between beer and consumption and LpA-I and fibrinogen levels did not reach statistical significance. Also, beer and spirits consumption had a higher correlation coefficient with SBP and DBP than wine (Table 2).

In Northern Ireland, the association of total alcohol intake with cardiovascular risk factors was similar to that observed in France, except that no significant correlations were found with BMI, total cholesterol, apoprotein B and fibrinogen (Table 2). When total alcohol consumption was split into wine, beer or spirits, the correlations differed according to the type of beverage consumed. Wine was significantly and negatively correlated with BMI, triglycerides, LpE:B and fibrinogen, whereas no relationship was found with SBP and DBP. Conversely, beer consumption was positively associated with SBP and DBP, triglycerides, HDL, apo-

Table 1

Clinical characteristics and alcohol consumption in France and Northern Ireland ${ }^{\mathrm{a}}$

\begin{tabular}{|c|c|c|c|}
\hline & $\begin{array}{l}\text { France } \\
(n=5362)\end{array}$ & $\begin{array}{l}\text { Northern Ireland } \\
(n=1367)\end{array}$ & Test \\
\hline Age (years) & $54.8 \pm 2.9$ & $54.6 \pm 2.9$ & $2.26^{\mathrm{NS}}$ \\
\hline BMI $\left(\mathrm{kg} / \mathrm{m}^{2}\right)$ & $26.4 \pm 3.3$ & $26.0 \pm 3.3$ & $4.53 * * *$ \\
\hline Years of school & $11.7 \pm 3.5$ & $11.2 \pm 2.6$ & $6.07 * * *$ \\
\hline Married & $4731(88)$ & $1162(85)$ & $10.30^{* * *}$ \\
\hline \multicolumn{4}{|l|}{ Smoking status } \\
\hline Non-smokers & $1463(27)$ & $352(26)$ & \\
\hline Ex smokers & $2403(45)$ & $474(35)$ & $75.33 * * *$ \\
\hline Current smokers & $1494(28)$ & $540(39)$ & \\
\hline $\begin{array}{l}\text { Wine (ml per } \\
\text { week) }\end{array}$ & $180(0-1890)$ & $0(0-661)$ & $46.54 * * *$ \\
\hline $\begin{array}{l}\text { Beer }(\mathrm{ml} \text { per } \\
\text { week) }\end{array}$ & $15(0-1750)$ & $132(0-3584)$ & $23.34 * * *$ \\
\hline $\begin{array}{l}\text { Spirits (ml per } \\
\text { week) }\end{array}$ & $12(0-1701)$ & $36(0-2272)$ & $10.89 * * *$ \\
\hline
\end{tabular}

\footnotetext{
${ }^{\text {a }}$ Results are expressed as mean \pm S.D. and as number of subjects and (percentage). BMI, body mass index. Analysis by $\chi^{2}$ for categorical variables, Student's $t$-test for age, BMI and years of school, and Wilcoxon rank sum test for alcohol consumption. ${ }^{\text {NS }}$, not significant; $* * *, P<0.001$.
} 
Table 2

Spearman univariate correlations between alcohol consumption and cardiovascular risk factors in France and Northern Ireland ${ }^{\mathrm{a}}$

\begin{tabular}{|c|c|c|c|c|c|c|c|c|}
\hline & \multicolumn{4}{|c|}{ France $(n=5362)$} & \multicolumn{4}{|c|}{ N. Ireland $(n=1368)$} \\
\hline & Total alcohol & Wine & Beer & Spirits & Total alcohol & Wine & Beer & Spirits \\
\hline BMI $\left(\mathrm{kg} / \mathrm{m}^{2}\right)$ & $0.07 * * *$ & $0.05^{* * *}$ & $0.05 * * *$ & $0.09 * * *$ & $0.05^{\mathrm{NS}}$ & $-0.10^{* * *}$ & $0.03^{\mathrm{NS}}$ & $0.10^{* * *}$ \\
\hline SBP (mmHg) & $0.13^{* * *}$ & $0.04 * *$ & $0.17 * * *$ & $0.08 * * *$ & $0.13 * * *$ & $-0.05^{\mathrm{NS}}$ & $0.10 * * *$ & $0.06^{*}$ \\
\hline DBP (mmHg) & $0.09^{* * *}$ & $0.02^{\mathrm{NS}}$ & $0.16^{* * *}$ & $0.06^{* * *}$ & $0.12 * * *$ & $-0.03^{\mathrm{NS}}$ & $0.08^{* *}$ & $0.06^{*}$ \\
\hline $\mathrm{TC}(\mathrm{mg} / \mathrm{dl})$ & $0.09 * * *$ & $0.07 * * *$ & $0.08 * * *$ & $0.07 * * *$ & $0.01^{\mathrm{NS}}$ & $0.08 * *$ & $-0.01^{\mathrm{NS}}$ & $0.01^{\mathrm{NS}}$ \\
\hline HDL (mg/dl) & $0.15^{* * *}$ & $0.13^{* * *}$ & $0.06^{* *}$ & $0.05 * * *$ & $0.17^{* * *}$ & $0.07^{*}$ & $0.10^{* * *}$ & $0.04^{\mathrm{NS}}$ \\
\hline TG (mg/dl) & $0.09 * * *$ & $0.04 * * *$ & $0.09 * * *$ & $0.04 * *$ & $0.08 * *$ & $-0.09 * * *$ & $0.08 * *$ & $0.06^{*}$ \\
\hline Apo A-I (mg/dl) & $0.19^{* * *}$ & $0.16^{* * *}$ & $0.11 * * *$ & $0.06^{* * *}$ & $0.22 * * *$ & $0.06^{*}$ & $0.13^{* * *}$ & $0.06^{*}$ \\
\hline Apo B (mg/dl) & $0.07 * * *$ & $0.04 * *$ & $0.06^{* * *}$ & $0.07 * * *$ & $-0.01^{\mathrm{NS}}$ & $-0.03^{\mathrm{NS}}$ & $0.01^{\mathrm{NS}}$ & $0.02^{\mathrm{NS}}$ \\
\hline Lp A-I (mg/dl) & $0.09 * * *$ & $0.08 * * *$ & $0.02^{\mathrm{NS}}$ & $0.04 * *$ & $0.08 * *$ & $0.11 * * *$ & $0.02^{\mathrm{NS}}$ & $0.01^{\mathrm{NS}}$ \\
\hline LpE:B (mg/dl) & $0.01^{\mathrm{NS}}$ & $-0.03^{*}$ & $0.04 * *$ & $0.02^{\mathrm{NS}}$ & $0.01^{\mathrm{NS}}$ & $-0.08^{* *}$ & $0.04^{\mathrm{NS}}$ & $-0.01^{\mathrm{NS}}$ \\
\hline $\mathrm{Lp}(\mathrm{a})(\mathrm{mg} / \mathrm{dl})$ & $-0.03^{*}$ & $-0.01^{\mathrm{NS}}$ & $-0.06 * * *$ & $-0.02^{\mathrm{NS}}$ & $0.01^{\mathrm{NS}}$ & $-0.01^{\mathrm{NS}}$ & $0.01^{\mathrm{NS}}$ & $0.01^{\mathrm{NS}}$ \\
\hline Fibrinogen $(\mathrm{g} / \mathrm{l})$ & $-0.06^{* * *}$ & $-0.08 * * *$ & $-0.01^{\mathrm{NS}}$ & $-0.03^{*}$ & $0.04^{\mathrm{NS}}$ & $-0.15^{* * *}$ & $0.08 * *$ & $0.02^{\mathrm{NS}}$ \\
\hline PAI-1 (UI/ml) & $0.18^{* * *}$ & $0.12 * * *$ & $0.14 * * *$ & $0.09 * * *$ & $0.11 * * *$ & $-0.05^{\mathrm{NS}}$ & $0.09 * * *$ & $0.06^{*}$ \\
\hline Factor VII (UI/ml) & $0.09 * * *$ & $0.05^{* * *}$ & $0.09 * * *$ & $0.06^{* * *}$ & $0.08^{* *}$ & $0.01^{\mathrm{NS}}$ & $0.06^{*}$ & $0.03^{\mathrm{NS}}$ \\
\hline
\end{tabular}

a BMI, body mass index; SBP, systolic blood pressure; DBP, diastolic blood pressure; TC, total cholesterol; TG, triglycerides (log-transformed); NS, not significant; *, $P<0.05 ; * *, P<0.01 ; * * *, P<0.001$.

protein A-I, fibrinogen and PAI-1 activity. Finally, consumption of spirits was significantly and positively correlated with BMI, SBP, DBP, total and HDL cholesterol and PAI-1 activity (Table 2).

\subsection{Multivariate analysis of the relationships between alcohol consumption and cardiovascular risk factors}

Multivariate analysis was conducted independently for France and Northern Ireland after adjusting for age, BMI and number of years in school (continuous), marital status (dichotomous) and tobacco smoking (2 dichotomous variables). In France, further adjustment on center was also performed. Only variables, which were significantly associated with total alcohol consumption on univariate analysis, in at least one country, were analyzed. The regression slopes correspond to the variation in the cardiovascular risk factor for an increase in one unit of alcohol per day (1 $\mathrm{U}=15 \mathrm{ml}$ of ethanol) for each type of beverage.

In France, the consumption of beer had a stronger effect on SBP, triglycerides and LpE:B than the consumption of wine, whereas the consumption of spirits had an intermediate effect on these parameters (Table 3). In Northern Ireland, the consumption of wine had a stronger positive effect on total and HDL cholesterol, apo A-I and LpA-I, and a stronger negative effect on fibrinogen than the consumption of alcohol from beer or spirits. Conversely, no statistically significant differences were found regarding the effects of each type of alcoholic beverage for the other cardiovascular risk factors (Table 3).

\subsection{Effect of type of alcoholic beverage}

The effect of alcoholic beverage independent of the amount of total alcohol consumed was studied by multiple regression with a dichotomous variable for each type of beverage, after adjusting for the total amount of alcohol consumed. In France, wine was associated with a decrease in SBP, DBP and fibrinogen levels, whereas beer was associated with an increase in PAI-1 activity levels (Table 4). Adjusting for the amount of alcohol for each beverage type did not alter the results (not shown).

In Northern Ireland, the consumption of wine was associated with an increase in LpA-I and a decrease in fibrinogen levels, while no difference was found between the three types of beverage regarding blood pressure and PAI-1 activity levels (Table 4). Again, adjusting for the amount of each type of alcoholic beverage did not change the results (not shown). Finally, no difference was found between the types of beverage in relation to Factor VII activity levels (Table 4).

\section{Discussion}

In the PRIME Study, it was decided to analyze the metabolic effects of alcohol consumption separately for France and Northern Ireland. This was because the drinking pattern as well as the relative amounts of each type of alcoholic beverage consumed differed greatly between the two countries. Alcohol consumption was evenly distributed throughout the week with only a slight increase at weekends in France, whereas Fridays and Saturdays accounted for two thirds of 
Table 3

Results of multivariate regression analysis between wine, beer and spirits consumption and cardiovascular risk factors for France and Northern Ireland ${ }^{\text {a }}$

\begin{tabular}{|c|c|c|c|c|c|c|c|c|}
\hline & \multicolumn{4}{|l|}{ France $(n=5362)$} & \multicolumn{4}{|c|}{ Northern Ireland $(n=1368)$} \\
\hline & Wine & Beer & Spirits & Test & Wine & Beer & Spirits & Test \\
\hline SBP (mmHg) & $0.55(0.32 ; 0.791)$ & $1.31(0.97 ; 1.64)$ & $0.09(-0.79 ; 0.98)$ & $7.63^{* * *}$ & $0.49(-1.82 ; 1.28)$ & $0.51(0.12 ; 0.90)$ & $0.56(-0.10 ; 1.228)$ & $0.01^{\mathrm{NS}}$ \\
\hline $\mathrm{DBP}(\mathrm{mmHg})$ & $0.25(-0.094 ; 0.40)$ & $0.484(0.26 ; 0.71)$ & $0.47(-0.11 ; 1.05)$ & $1.51^{\mathrm{NS}}$ & $0.08(-1.19 ; 1.35)$ & $0.32(0.11 ; 0.54)$ & $0.69(0.32 ; 1.05)$ & $1.47^{\mathrm{NS}}$ \\
\hline $\mathrm{TC}(\mathrm{mg} / \mathrm{dl})$ & $1.47(0.90 ; 2.04)$ & $0.47(-0.35 ; 1.29)$ & $2.62(0.50 ; 4.74)$ & $2.90^{\mathrm{NS}}$ & $5.69(0.82 ; 10.55)$ & $-0.51(-1.33 ; 0.32)$ & $0.38(-1.02 ; 1.78)$ & $3.80 *$ \\
\hline HDL (mg/dl) & $1.13(0.93 ; 1.33)$ & $0.91(0.64 ; 1.18)$ & $0.45(-0.26 ; 1.16)$ & $2.05^{\mathrm{NS}}$ & $3.70(2.24 ; 5.15)$ & $0.89(0.64 ; 1.13)$ & $0.93(0.51 ; 1.35)$ & $7.23^{* * *}$ \\
\hline $\mathrm{TG}(\mathrm{mg} / \mathrm{dl})$ & $1.95(0.578 ; 3.32)$ & $6.08(4.10 ; 8.06)$ & $3.97(-1.15 ; 9.09)$ & $5.67 * *$ & $-2.39(-8.24 ; 3.47)$ & $-0.14(-1.13 ; 0.85)$ & $-0.17(-1.85 ; 1.52)$ & $0.29^{\mathrm{NS}}$ \\
\hline Apo A-I (mg/dl) & $2.15(1.778 ; 2.52)$ & $1.66(1.13 ; 2.19)$ & $1.99(0.60 ; 3.38)$ & $1.10^{\mathrm{NS}}$ & $7.34(4.54 ; 10.13)$ & $1.52(1.05 ; 1.99)$ & $1.73(0.92 ; 2.53)$ & $8.57^{* * *}$ \\
\hline Apo B (mg/dl) & $0.55(0.04 ; 1.06)$ & $0.85(0.13 ; 1.58)$ & $2.70(0.84 ; 4.56)$ & $2.25^{\mathrm{NS}}$ & $0.08(-3.97 ; 4.12)$ & $-0.95(-1.63 ;-0.26)$ & $-0.37(-1.54 ; 0.79)$ & $0.48^{\mathrm{NS}}$ \\
\hline Lp A-I (mg/dl) & $0.62(0.44 ; 0.80)$ & $0.32(0.07 ; 0.58)$ & $0.49(-0.16 ; 1.14)$ & $1.93^{\mathrm{NS}}$ & $2.35(1.11 ; 3.58)$ & $0.33(0.12 ; 0.541)$ & $0.46(0.11 ; 0.82)$ & $5.43 * *$ \\
\hline $\mathrm{LpE}: \mathrm{B}(\mathrm{mg} / \mathrm{dl})$ & $0.02(-0.27 ; 0.31)$ & $0.98(0.57 ; 1.39)$ & $0.13(-0.95 ; 1.21)$ & $6.87 * *$ & $-0.83(-3.44 ; 1.79)$ & $-0.40(-0.84 ; 0.05)$ & $0.50(-1.25 ; 0.25)$ & $0.08^{\mathrm{NS}}$ \\
\hline Fibrinogen $(\mathrm{g} / \mathrm{l})$ & $-0.02(-0.04 ;-0.01)$ & $0.01(-0.02 ; 0.02)$ & $-0.01(-0.07 ; 0.04)$ & $1.55^{\mathrm{NS}}$ & $-0.21(-0.33 ;-0.08)$ & $0.01(-0.02 ; 0.03)$ & $-0.01(-0.04 ; 0.03)$ & $6.07 * *$ \\
\hline PAI-1 (UI/ml) & $0.54(0.40 ; 0.68)$ & $0.69(0.49 ; 0.89)$ & $0.99(0.47 ; 1.51)$ & $1.69 \mathrm{NS}$ & $0.10(-1.24 ; 1.44)$ & $0.39(0.16 ; 0.62)$ & $0.10(-0.29 ; 0.49)$ & $0.89^{\mathrm{NS}}$ \\
\hline Factor VII (UI/ml) & $0.01(0.004 ; 0.02)$ & $0.02(0.01 ; 0.03)$ & $0.016(-0.01 ; 0.04)$ & $2.04^{\mathrm{NS}}$ & $0.04(-0.01 ; 0.08)$ & $0.01(0.01 ; 0.02)$ & $0.01(-0.01 ; 0.02)$ & $0.56^{\mathrm{NS}}$ \\
\hline
\end{tabular}

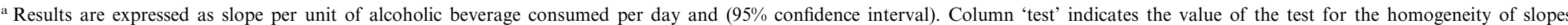
(wine $=$ beer $=$ spirits). SBP, systolic blood pressure; DBP, diastolic blood pressure; TC, total cholesterol; TG, triglycerides. NS, not significant;,$P<0.05$; $^{* *}, P<0.01$; ${ }^{* *}, P<0.001$. 
Table 4

Effects of type of beverage for France and Northern Ireland ${ }^{\mathrm{a}}$

\begin{tabular}{|c|c|c|c|c|c|c|c|c|}
\hline & \multicolumn{4}{|l|}{ France $(n=5362)$} & \multicolumn{4}{|c|}{ Northern Ireland $(n=1368)$} \\
\hline & Wine & Beer & Spirits & Test & Wine & Beer & Spirits & Test \\
\hline $\mathrm{SBP}(\mathrm{mm} \mathrm{Hg})$ & $-2.20(-3.78 ;-0.62)$ & $0.89(-0.07 ; 1.84)$ & $-0.59(-1.55 ; 0.36)$ & $6.56^{* *}$ & $0.41(-2.24 ; 3.06)$ & $0.88(-1.79 ; 3.55)$ & $-0.24(-2.40 ; 1.92)$ & $0.26^{\mathrm{NS}}$ \\
\hline $\mathrm{DBP}(\mathrm{mmHg})$ & $-1.11(-2.14 ;-0.07)$ & $0.35(-0.28 ; 0.97)$ & $-0.31(-0.94 ; 0.32)$ & $3.33 *$ & $0.21(-1.24 ; 1.66)$ & $0.27(-1.20 ; 1.74)$ & $-0.39(-1.56 ; 0.79)$ & $0.34^{\mathrm{NS}}$ \\
\hline $\mathrm{TG}(\mathrm{mg} / \mathrm{dL})$ & $-0.03(-0.12 ; 0.07)$ & $0.02(-0.04 ; 0.07)$ & $-0.02(-0.11 ; 0.01)$ & $0.58 \mathrm{NS}$ & $-0.02(-0.08 ; 0.05)$ & $0.03(-0.04 ; 0.10)$ & $-0.01(-0.07 ; 0.04)$ & $0.65^{\mathrm{NS}}$ \\
\hline Lp A-I (mg/dL) & $0.01(-0.01 ; 0.02)$ & $-0.001(-0.01 ; 0.01)$ & $0.01(-0.01 ; 0.01)$ & $1.69^{\mathrm{NS}}$ & $0.02(0.01 ; 0.03)$ & $-0.01(-0.02 ; 0.01)$ & $0.01(-0.01 ; 0.02)$ & $3.60^{*}$ \\
\hline Fibrinogen $(\mathrm{g} / \mathrm{L})$ & $-0.20(-0.30 ;-0.11)$ & $-0.05(-0.11 ; 0.01)$ & $-0.04(-0.10 ; 0.02)$ & $4.51 *$ & $-0.15(-0.29 ;-0.01)$ & $0.08(-0.06 ; 0.22)$ & $-0.01(-0.13 ; 0.11)$ & $3.46^{*}$ \\
\hline PAI-1 (UI/mL) & $0.10(-0.85 ; 1.04)$ & $0.90(0.33 ; 1.47)$ & $-1.40(-0.71 ; 0.43)$ & $3.33 *$ & $-0.11(-1.64 ; 1.42)$ & $0.22(-1.35 ; 1.79)$ & $-0.78(-2.03 ; 0.47)$ & $0.61^{\mathrm{NS}}$ \\
\hline Factor VII (UI/mL) & $0.01(-0.04 ; 0.05)$ & $0.02(-0.01 ; 0.05)$ & $0.01(-0.01 ; 0.04)$ & $0.13^{\mathrm{NS}}$ & $0.03(-0.02 ; 0.09)$ & $0.04(-0.01 ; 0.09)$ & $0.01(-0.04 ; 0.05)$ & $0.59^{\mathrm{NS}}$ \\
\hline
\end{tabular}

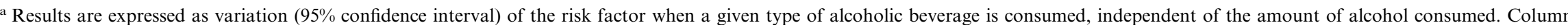

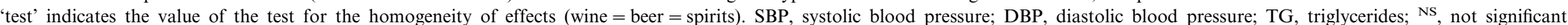
*,$P<0.05$; **,$P<0.01$; *** $P<0.001$. 
total alcohol consumption in Northern Ireland [45]. Also, wine was the predominant alcoholic beverage in France, whereas beer was the predominant beverage in Northern Ireland. Since the metabolic effects of alcohol can differ according to the pattern of intake [46], pooling the data from the two countries was considered inappropriate, as some of the effects attributed to alcohol consumption could in fact be due to differences in patterns of intake between the two countries. Also, this analysis was restricted to drinkers, and it has been shown that drinkers and teetotallers differ regarding several clinical characteristics [47]. Indeed, in both countries, drinkers had a higher frequency of smoking than non-drinkers, whereas in France drinkers had a higher educational level and also a higher BMI than non-drinkers, no such differences being observed in Northern Ireland. Thus, it is possible that some relationships between alcohol consumption and cardiovascular risk factors observed among drinkers might be partly confounded by the clinical characteristics of drinkers.

On univariate analysis, total alcohol consumption was significantly and positively associated with blood pressure levels, triglycerides, HDL parameters, PAI-1 and Factor VII activity in both countries. Those findings are in agreement with other studies [20,21,26,48] and suggest that this effect could be attributed solely to the amount of ethanol and not to the type of alcoholic beverage consumed. Conversely, total alcohol consumption was associated with a decrease in $L$ (a) in France, whereas no significant relationship has been found in Northern Ireland. Those findings partly support the results of other studies [27-29] where alcohol consumption was associated with a decrease in $\mathrm{Lp}$ (a) levels. The differences observed in France and Northern Ireland for $\mathrm{Lp}$ (a) might be attributable to the genetic characteristics of subjects in each country, as has been demonstrated for HDL metabolism [40,41]. Interestingly, the coefficients obtained for each beverage regarding LpA-I in France were closed to those observed in a previous publication [48].

When total alcohol consumption was split into wine, beer and spirits, significant differences were found for the effects of each type of beverage on cardiovascular risk factors. In France, beer consumption led to a larger increase in SBP levels, triglycerides and LpE:B than wine or spirits consumption. The reasons for a differential effect of the amount of ethanol contained in each beverage in France are currently unknown and can only be speculated. For instance, the differential effect of wine and beer on blood pressure is in agreement with a previous study where wine intake was associated with lower risk for stroke relative to beer and spirits [49]. Also, since alcohol content of beer is lower than that of wine and spirits, a larger volume of beer must be drunk to achieve a given amount of alcohol. This higher intake could influence blood pressure levels and partly explain the stronger relationship of alcohol derived from beer with blood pressure levels observed in France. Finally, beer intake has been associated with hyponatremia due to the hyposmolality of the beer ingested [50]; this would lead to secondary hyperaldosteronism, with an increase in vascular tone and blood pressure levels. Although a previous study found no increase in aldosterone levels among alcoholic men [51], the effect of alcohol intake on mineralocorticoid status is poorly known. The lesser effect of beer on blood pressure levels found in Northern Ireland (although with a similar pattern as in France regarding DBP) might partly be due to the large amounts of beer consumed relative to wine, which would complicate the analysis as few people consume wine there. Also, the pattern of intake in Northern Ireland is different from that in France, Fridays and Saturdays accounting for almost $70 \%$ of the weekly alcohol consumption. This drinking pattern in Northern Ireland, as opposed to the continuous pattern of intake in France, might also obscure the relationships between alcohol consumption and blood pressure levels.

In both countries, the amount of alcohol derived from each type of beverage was significantly related to higher HDL parameters (HDL cholesterol, apo A-I and LpA-I), but in Northern Ireland wine consumption was associated with greater levels of these parameters. Again, the reasons for this difference are not straightforward. Although a direct effect of wine on HDL parameters cannot be excluded, it has been shown that Northern Irish subjects who drink wine have a better life-style than subjects who drink other types of alcoholic beverages [45]. For instance, Northern Irish subjects who drink mainly wine have their lunch more frequently at home and use low fat spreads more frequently (52 vs. $39 \%, P<0.01$ ) than subjects who drink mainly beer or spirits, who in turn more frequently use butter. Also, in Southwestern France, wine consumption was negatively associated with fat intake (Spearman rank correlation between wine and fat caloric density $=-0.19, P<0.001)$, whereas no such relationship was found for beer $(r=0.03, P=0.28)$ (Marques-Vidal, unpublished observations). Thus, although potential confounders were included in the model (smoking, educational level and marital status), it is possible that some other factors related to both beverage preference and to cardiovascular risk factor levels such as nutritional intake were unaccounted for in our study.

In both countries, the amount of alcohol derived from wine tended to be associated with lower fibrinogen levels than the other types of alcoholic beverages. In addition, wine intake was associated with a decrease in fibrinogen independent of the amount of alcohol consumed. Those findings do not support the results of other studies [52], which indicated that alcohol amount 
and not wine per se decreased fibrinogen levels, and indicate the need for further studies to clarify this point.

The effect of beverage type (and not of the amount of alcohol) on SBP, DBP and PAI-1 activity observed in France and for fibrinogen in both countries raises the question as to whether alcoholic beverages contain other biochemical components apart from alcohol which might influence cardiovascular risk factors. Red wine contains phenolic compounds which have been shown to reduce LDL oxidation $[30,34,35]$. Wine has also been shown to increase fibrinolysis $[53,54]$ and to decrease platelet aggregation [55], possibly because of the small amounts of acetylsalicylic acid present [56], although this hypothesis has been questioned [57] and the antiplatelet effect of wine has been attributed to alcohol rather than other substances [52]. Also, as stated previously, beer consumption could be associated with a higher frequency of hyponatremia due to the low solute content of beer [50]. Another possibility is that this beverage effect corresponds in fact to other factors related to the consumption of this particular type of alcoholic beverage. For instance, beer drinkers have a higher waist/hip ratio than other drinkers [58]. Indeed, in this study, waist/hip ratio was significantly associated with the consumption of beer (Spearman correlation coefficient $=0.14, P<0.001$ ), and to a lesser extent with the consumption of wine (Spearman correlation coefficient $=0.06, P<0.001$ ), but not with the consumption of spirits. Nevertheless, the beverage effect remained after adjusting for waist/hip ratio (not shown). Furthermore, the choice of type of beverage is also determined by socio-economic factors [59], lifestyle and personality [60], and a recent study has shown that moderate wine drinking appears to be related to good self-rated health [61]. Thus, as stated previously, it is possible that some other factors simultaneously related to beverage preference and to cardiovascular risk factor levels were unaccounted for in our study.

Most studies that have found an inverse relationship between wine and coronary artery disease were carried out in populations whose alcohol intake was almost exclusively due to wine consumption [62]. Similarly, studies, which have found an inverse relationship between beer or spirits and coronary artery disease, have concerned populations with a high intake of these types of alcohol $[6,63]$. Finally, in many instances where only one beverage type was inversely related to coronary artery disease, a similar but non-significant trend was also found for the other alcoholic beverages. Thus, the available evidence suggests that no particular type of beverage is superior against coronary artery disease. Those findings are not supported by the results of our study, which found in France (but not in Northern Ireland) a beverage-specific association with most cardiovascular risk factors. Our data, thus, raise the ques- tion whether the pattern of intake could also influence the effect of alcohol on cardiovascular risk factors and, thus, cardiovascular disease as it has been suggested by others [64]. Finally, it should be noted that most prospective studies on alcohol consumption and coronary artery disease have been carried out in countries where alcohol intake is not homogeneous throughout the week, and most of them could not assess the effect of the drinking pattern on the incidence of cardiovascular disease [65]. Although some authors have shown that both weekly and daily drinking decrease coronary artery disease risk [8], to our knowledge, the PRIME Study is the only on-going prospective study which will enable the simultaneous analysis of the effects of alcohol consumption and of the drinking pattern (chronic or binge) on the incidence of coronary artery disease.

In summary, our data indicate that total alcohol consumption is significantly related to most lipid, lipoprotein and haemostatic risk factors, but that the magnitude of the effect depends on the type of alcoholic beverage, which could also influence risk factor levels via non-alcoholic components.

\section{The PRIME study}

The PRIME Study is organized under an agreement between INSERM and the Merck, Sharp and DohmeChibret laboratory, with the following participating Laboratories.

- The Strasbourg MONICA Project, Department of Epidemiology and Public Health, Faculty of Medicine, Strasbourg, France (D. Arveiler, B. Haas).

- The Toulouse MONICA Project, INSERM U518, Department of Epidemiology, Paul-Sabatier-Toulouse Purpan University, Toulouse France (J. Ferrières, J.B. Ruidavets, P. Marques-Vidal).

- The Lille MONICA Project, INSERM U508, Pasteur Institute, Lille, France (P. Amouyel, M. Montaye).

- the Department of Epidemiology and Public Health, The Queen's University of Belfast, Belfast, Northern Ireland (A. Evans, J. Yarnell).

- The Department of Atherosclerosis, SERLIA-INSERM U325, Lille, France (G. Luc, JM. Bard).

- The Laboratory of Haematology, La Timone Hospital, Marseilles, France (I. Juhan-Vague).

- The Laboratory of Endocrinology, INSERM U326, Toulouse, France (B. Perret).

- The Vitamin Research Unit, The University of Bern, Bern, Switzerland (F. Gey).

- The Trace Element Laboratory, Department of Medicine, The Queen's University of Belfast, Belfast, Northern Ireland (D. McMaster).

- The DNA Bank, INSERM U525/SC7, Paris, France (F. Cambien). 
- The Coordinating Center, INSERM U258, Villejuif, France (P. Ducimetière, P.Y. Scarabin, A. Bingham).

\section{Acknowledgements}

The PRIME Study is supported by grants from Merck, Sharp and Dohme-Chibret (France) and from the Department of Health and Social Service and the Northern Ireland Chest, Heart and Stroke Association (Northern Ireland). We thank the following organizations which allowed the recruitment of the PRIME subjects; the Health screening centers organized by the Social Security of Lille (Institut Pasteur), Strasbourg, Toulouse and Turcoing; Occupational Medicine services of Haute-Garonne, the Urban Community of Strasbourg, the Association Inter-entreprises des Services Médicaux du Travail de Lille et environs; the Comité pour le Développement de la Médecine du Travail; the Mutuelle Générale des PTT du Bas-Rhin; the Laboratoire d'Analyes de l'Institut de Chimie Biologique de la Faculté de Médecine de Strasbourg.

\section{References}

[1] Marmot MG, Rose G, Shipley MJ, Thomas BJ. Alcohol and mortality: a U-shaped curve. Lancet 1981;1:580-3.

[2] Kozarevic D, Vojvodic N, Gordon T, Kaelber CT, McGee D, Zukel WJ. Drinking habits and coronary heart disease: the Yugoslavia cardiovascular disease study. Am J Epidemiol 1982;116:748-58.

[3] Friedman LA, Kimball AW. Coronary heart disease mortality and alcohol consumption in Framingham. Am $\mathbf{J}$ Epidemiol 1986;124:481-9.

[4] Moore RD, Pearson TA. Moderate alcohol consumption and coronary artery disease. A review. Medicine 1986;65:242-67.

[5] Jackson R, Scragg R, Beaglehole R. Alcohol consumption and risk of coronary heart disease. Br Med J 1991;303:211-6.

[6] Rimm EB, Giovannucci EL, Willett WC, et al. Prospective study of alcohol consumption and risk of coronary disease in men. Lancet 1991;338:464-8.

[7] Rimm EB, Klatsky A, Grobbee D, Stampfer MJ. Review of moderate alcohol consumption and reduced risk of coronary heart disease: is the effect due to beer, wine, or spirits? Br Med J 1996;312:731-6.

[8] Camargo CA Jr, Stampfer MJ, Glynn RJ, Grodstein F, Gaziano JM, Manson JE, et al. Prospective study of moderate alcohol consumption and mortality in US male physicians. Arch Intern Med 1997;157:79-85.

[9] Tunstall-Pedoe H, Woodward M, Tavendale R, A'Brook R, McCluskey MK. Comparison of the prediction by 27 different factors of coronary heart disease and death in men and women of the Scottish heart health study: cohort study. Br Med J 1997;315:722-9.

[10] Albert CM, Manson JE, Cook NR, Ajani UA, Gaziano JM, Hennekens $\mathrm{CH}$. Moderate alcohol consumption and the risk of sudden cardiac death among US male physicians. Circulation 1999;100:944-50.
[11] Rosenberg L, Slone D, Shapiro S, Kaufman DW, Miettinen OS, Stolley PD. Alcoholic beverages and myocardial infarction in young women. Am J Public Health 1981;71:82-5.

[12] Renaud S, De Lorgeril M. Wine, alcohol, platelets and the French paradox for coronary heart disease. Lancet 1992;339:1523-6.

[13] Goldberg DM. Does wine work? Clin Chem 1995;41:14-6.

[14] Grønbæk M, Sørensen TIA. Alcohol consumption and risk of coronary heart disease. Studies suggest that wine has additional effect to that of ethanol. Br Med J 1996;313:365.

[15] Hennekens CH, Willet W, Rosner B, Cole DS, Mayrent SL. Effects of beer, wine, and liquor in coronary deaths. J Am Med Assoc 1979;242:1973-4.

[16] Marques-Vidal P, Ducimetière P, Evans A, Cambou JP, Arveiler D. Alcohol consumption and myocardial infarction: a case-control study in France and Northern Ireland. Am J Epidemiol 1996;143:1089-93.

[17] Gaziano JM, Hennekens CH, Godfried SL, et al. Type of alcoholic beverage and risk of myocardial infarction. Am $\mathbf{J}$ Cardiol 1999;83:52-7.

[18] Puchois P, Ghalim N, Zylberberg G, Fievet P, Demarquilly C, Fruchart JC. Effect of alcohol intake on human apolipoprotein A-I-containing lipoprotein subfractions. Arch Intern Med 1990;150:1638-41.

[19] Amarasuriya RN, Gupta AK, Civen M, Horn YC, Maeda T, Kashyap ML. Ethanol stimulated apolipoprotein A-I secretion by human hepatocytes: implications for a mechanism for atherosclerosis protection. Metabolism 1992;41:827-32.

[20] Gaziano JM, Buring JL, Breslow JL, Goldhaber SZ, Rosner B, VanDenburgh M, et al. Moderate alcohol intake, increased levels of high-density lipoprotein and its subfractions, and decreased risk of myocardial infarction. New Engl J Med 1993;329:182934.

[21] Marques-Vidal P, Cambou JP, Nicaud V, et al. Cardiovascular risk factors and alcohol consumption in France and Northern Ireland. Atherosclerosis 1995;115:225-32.

[22] Dashti N, Franklin A, Abrahamson DR. Effect of ethanol on the synthesis and secretion of apo A-I- and apoB-containing lipoproteins in HepG2 cells. J Lipid Res 1996;37:810-24.

[23] Lecomte E, Herberth B, Paille F, Steinmetz J, Artur Y, Siest G. Changes in serum apolipoprotein and lipoprotein profile by chronic alcohol consumption and withdrawal: determinant effect on heart disease? Clin Chem 1996;42:1666-75.

[24] Parker DR, McPhillips JB, Derby CA, Gans KM, Lasater TM, Carleton RA. High-density-lipoprotein cholesterol and types of alcoholic beverages consumed among men and women. Am J Public Health 1996;86:1022-7.

[25] Paunio MJV, Gref CG, Heinonen OP. Serum high density lipoprotein cholesterol, alcohol, and coronary mortality in male smokers. Br Med J 1996;312:1200-3.

[26] Rimm EB, Williams P, Fosher K, Criqui M, Stampfer MJ. Moderate alcohol intake and lower risk of coronary heart disease: meta- analysis of effects on lipids and haemostatic factors. Br Med J 1999;319:1523-8.

[27] Kervinen K, Savolainen MJ, Kesaniemi YA. A rapid increase in lipoprotein (a) levels after ethanol withdrawal in alcoholic men. Life Sci 1991;48:2183-8.

[28] Huang CM, Elin RJ, Ruddel M, Schmitz J, Linnoila M. The effect of alcohol withdrawal on serum concentrations of $L p(a)$, apolipoproteins A-1 and B, and lipids. Alcohol Clin Exp Res 1992;16:895-8.

[29] Paasilta M, Kervinen K, Rantala AO, et al. Social alcohol consumption and low $\mathrm{Lp}(\mathrm{a})$ lipoprotein concentrations in middle aged Finnish men: population based study. $\mathrm{Br}$ Med $\mathbf{J}$ 1998;316:594-5.

[30] Frankel EN, Kanner J, German JB, Parks E, Kinsella JE. Inhibition of oxidation of human low-density lipoprotein by phenolic substances in red wine. Lancet 1993;341:454-7. 
[31] Kondo K, Matsumoto A, Kurata H, et al. Inhibition of oxidation of low-density lipoprotein with red wine. Lancet 1994;344:1152.

[32] Serafini M, Ghiselli A, Ferro-Luzzi A. Red wine, tea, and antioxidants. Lancet 1994;344:626.

[33] Abu-Amsha R, Croft KD, Puddey IB, Proudfoot JM, Beilin U. Phenolic content of various beverages determines the extent of inhibition of human serum and low-density lipoprotein oxidation in vitro: identification and mechanism of action of some cinnamic acid derivatives from red wine. Clin Chem 1996;91:44958.

[34] Carbonneau MA, Léger CL, Monnier L, et al. Supplementation with wine phenolic compounds increases the antioxidant capacity of plasma and vitamin E of low-density lipoprotein without changing the lipoprotein $\mathrm{Cu}^{2+}$-oxidizability: possible explanation by phenolic location. Eur J Clin Nutr 1997;51:682-90.

[35] Kerry NL, Abbey M. Red wine and fractionated phenolic compounds prepared from red wine inhibit low density lipoprotein oxidation in vitro. Atherosclerosis 1997;135:93-102.

[36] Mérillon J-M, Fauconneau B, Teguo PW, Barrier L, Vercauteren J, Huguet F. Antioxidant activity of the stilbene astringin, newly extracted from Vitis vinifera cell cultures. Clin Chem 1997;43:1092-3.

[37] Mayer EJ, Newman B, Quesenberry CP, Friedman GD, Selby JV. Alcohol consumption and insulin concentrations. Role of insulin in associations of alcohol intake with high-density lipoprotein cholesterol and triglycerides. Circulation 1993;88:21907.

[38] Nishiwaki M, Ishikawa T, Ito T, et al. Effects of alcohol on lipoprotein lipase, hepatic lipase, cholesteryl ester transfer protein, and lecithin: cholesterol acyltransferase in high-density lipoprotein cholesterol elevation. Atherosclerosis 1994;111:99109.

[39] Ito T, Nishiwaki M, Ishikawa T, Nakamura H. CETP and LCAT activities are unrelated to smoking and moderate alcohol consumption in healthy normolipidemic men. Jpn Circulation $\mathbf{J}$ 1995;59:541-6.

[40] Hannuksela ML, Liinamaa MJ, Kesaniemi YA, Savolainen MJ. Relation of polymorphisms in the cholesteryl ester transfer protein gene to transfer protein activity and plasma lipoprotein levels in alcohol drinkers. Atherosclerosis 1994;110:35-44.

[41] Fumeron F, Betoulle D, Luc G, et al. Alcohol intake modulates the effect of a polymorphism of the cholesteryl ester transfer protein gene on plasma high density lipoprotein and the risk of myocardial infarction. J Clin Invest 1995;96:1664-71.

[42] Brozovic M, Stirling Y, Harricks C, North WRS, Meade TW. Factor VII in an industrial population. $\mathrm{Br} \mathrm{J}$ Haematol 1974;28:381-91.

[43] Puchois P, Kandoussi A, Fievet P, et al. Apolipoprotein A-I containing lipoproteins in coronary artery disease. Atherosclerosis $1987 ; 68: 35-40$.

[44] Kimball AW, Friedman LA. Alcohol consumption regression models for distinguishing between beverage type effects and beverage prefence effects. Am J Epidemiol 1992;135:1279-86.

[45] Marques-Vidal P, Arveiler D, Evans A, et al. Patterns of alcohol consumption in middle-aged men from France and Northern Ireland. The PRIME Study. Eur J Clin Nutr 2000;54:321-8.
[46] DiPadova C, Worner TM, Julkunen RJ, Lieber CS. Effects of fasting and chronic alcohol consumption on the first-pass metabolism of ethanol. Gastroenterology 1987;92:1169-73.

[47] Pearson DC, Grothaus LC, Thompson RS, Wagner EH. Smokers and drinkers in a health maintenance organization population: lifestyles and health status. Prev Med 1987;16:783-95.

[48] Luc G, Bard J, Evans A, Arveiler D, et al. The relationship between apolipoprotein AI-containing lipoprotein fractions and environmental factors: the prospective epidemiological study of myocardial infarction (PRIME study). Atherosclerosis 2000;152:399-405.

[49] Truelsen T, Gronbaek M, Schnohr P, Boysen G. Intake of beer, wine, and spirits and risk of stroke: the Copenhagen city heart study. Stroke 1998;29:2467-72.

[50] Fenves AZ, Thomas S, Knochel JP. Beer potomania: two cases and review of the literature. Clin Nephrol 1996;45:61-4.

[51] Dominiczak AF, Semple PF, Fraser R, Lever AF, Wallace AM. Hypokalaemia in alcoholics. Scott Med J 1989;34:489-94.

[52] Pellegrini N, Pareti FI, Stabile F, Brusamolino A, Simonetti P. Effects of moderate consumption of red wine on platelet aggregation and haemostatic variables in healthy volunteers. Eur $\mathbf{J}$ Clin Invest 1996;50:209-13.

[53] Hendricks HFJ, Veenstra J, Velthuis-te Wierick EJM, Shaafsma G, Kluft C. Effect of moderate dose of alcohol with evening meal on fibrinolytic factors. Br Med J 1994;308:1003-6.

[54] Olsen H, Osterud B. Effects of ethanol on human blood fibrinolysis and coagulation. Alcohol Alcohol 1987;1(Suppl):591-4.

[55] Owens CK, McIntire LV, Lasslo A. Ethanol inhibition of thrombus formation on collagen-coated glass. Thromb Haemost 1990;63:510-6.

[56] Muller CJ, Fugelsang KC. Take two glasses of wine and see me in the morning. Lancet 1994;343:1428-9.

[57] Janssen PLTMK, Katan MB, Hollman PCH, Venemo DP. No aspirin in red wine. Lancet 1994;344:762.

[58] Duncan BB, Chambless LE, Schmidt MI, et al. Association of the waist-to-hip ratio is different with wine than with beer or hard liquor consumption. Atherosclerosis Risk in Communities Study Investigators. Am J Epidemiol 1995;142:1034-8.

[59] Westin S. Mortality associated with wines, beers, and spirits. Study confounded by lack of correction for social class. Br Med J 1995;311:1167.

[60] Burke V, Puddey IB, Beilin LJ. Mortality associated with wines, beers, and spirits. Br Med J 1995;311:1166-7.

[61] Poikolanen K, Vartiainen E. Wine and good subjective health. Am J Epidemiol 1999;150:47-50.

[62] Farchi G, Fidanza F, Mariotti S, Menotti A. Alcohol and mortality in the Italian rural cohorts of the Seven Countries Study. Int J Epidemiol 1992;21:74-81.

[63] Yano K, Rhoads GG, Kagan A. Coffee, alcohol, and risk of coronary heart disease among Japanese men living in Hawaii. New Engl J Med 1977;297:405-9.

[64] Kauhanen J, Kaplan GA, Goldberg DD, Cohen RD, Lakka TA, Salonen JT. Frequent hangovers and cardiovascular mortality in middle-aged men. Epidemiology 1997;8:310-4.

[65] Camargo Jr CA, Stampfer MJ, Glynn RJ, et al. Moderate alcohol consumption and risk for angina pectoris or myocardial infarction in US male physicians. Ann Intern Med 1997;126:372-5. 